\title{
Folic acid supplements and risk for oral clefts in the newborn: a population-based study
}

\author{
Trude Gildestad $^{1,2 *}$, Tone Bjørge ${ }^{1,3}$, Stein Emil Vollset ${ }^{1,4}$, Kari Klungsøyr ${ }^{1,4}$, Roy Miodini Nilsen ${ }^{1,5}$, \\ $\varnothing y$ stein Ariansen Haaland ${ }^{1,6}$ and Nina $\varnothing_{\text {yen }}{ }^{1,7}$ \\ ${ }^{1}$ Department of Global Public Health and Primary Care, University of Bergen, N-5020 Bergen, Norway \\ ${ }^{2}$ Department of Dermatology, Haukeland University Hospital, N-5021 Bergen, Norway \\ ${ }^{3}$ Cancer Registry of Norway, N-0304 Oslo, Norway \\ ${ }^{4}$ Medical Birth Registry of Norway/Norwegian Institute of Public Health, N-5018 Bergen/N-0456 Oslo, Norway \\ ${ }^{5}$ Centre for Clinical Research, Haukeland University Hospital, N-5021 Bergen, Norway \\ ${ }^{6}$ Department of Pediatrics, Haukeland University Hospital, N-5021 Bergen, Norway \\ ${ }^{7}$ Center for Medical Genetics and Molecular Medicine, Haukeland University Hospital, N-5021 Bergen, Norway \\ (Submitted 9 April 2015 - Final revision received 6 July 2015 - Accepted 13 July 2015 - First published online 7 September 2015)
}

\section{Abstract}

Results from previous studies on maternal folic acid intake and infant oral clefts are inconclusive. The aim of the present study was to investigate the association between women's use of folic acid and/or multivitamin supplements and the risk for oral cleft in the newborn. We used data from the Medical Birth Registry of Norway based on all births in Norway from 1999 to 2013. A total of 528220 women had 880568 pregnancies, resulting in 896674 live births and stillbirths, of which 1623 had oral clefts (isolated oral clefts, $n$ 1311; non-isolated oral clefts, $n$ 312). Altogether, $21.5 \%$ of women were vitamin supplement users before pregnancy. The birth prevalence of oral clefts was $1 \cdot 81 / 1000$ live births and stillbirths. Relative risks (RR) were estimated with log-binomial regression. For pregnancies with maternal use of vitamins, the adjusted RR for clefts overall was 0.90 (95\% CI 0.79, 1.04). The adjusted RR for cleft palate only ( $n$ 586) was 0.84 (95\% CI $0.66,1 \cdot 06)$ and that for cleft lip with or without cleft palate $(n$ 1037) was 0.94 (95\% CI $0.79,1.13)$. Associations were stronger for cleft cases that occurred in combination with other malformations (adjusted RR $0.63 ; 95 \% \mathrm{CI} 0.45,0 \cdot 88$ ), although vitamin supplements provided no protection against isolated clefts (adjusted RR 0.98; $95 \%$ CI 0.84, 1.15). In conclusion, our study demonstrates no statistically significant association between vitamin use and isolated oral clefts. However, we found lower risk for oral clefts that occurred in combination with other malformations.

Key words: Folic acid: Multivitamins: Oral clefts: Reproduction: Health promotion: Epidemiology

Intervention studies have demonstrated that maternal use of folic acid supplements before and early in pregnancy reduces the risk for neural tube defects in the fetus ${ }^{(1-6)}$. There is increasing evidence that maternal intake of folic acid supplements in early pregnancy may also reduce the risk for oral clefts. However, the findings are divergent, and the effect of folic acid on oral clefts is debated ${ }^{(7-11)}$.

Facial structures that form the embryonic lip fuse during the 5th and 6th weeks of life, whereas the palatal shelves fuse during 7-10 weeks. Oral clefts occur when the lips and/or the roof of the mouth do not fuse properly ${ }^{(12)}$. On the basis of Global Burden of Disease regions, Mossey \& Modell ${ }^{(13)}$ have estimated an average world birth prevalence of nonchromosomal oral clefts at $1 \cdot 25 / 1000$ births. In Norway, the prevalence is about $2 \cdot 2 / 1000$ live births and stillbirths after
16 weeks of gestation, which is one of the highest prevalence levels in Europe ${ }^{(14)}$.

In general, oral clefts are classified into two primary categories: cleft palate only (CPO) and cleft lip with or without cleft palate (CL(P)). These two types may have distinct causal mechanisms. The majority of oral clefts are described as isolated, meaning that no accompanying birth defects are present. CPO, however, is more often combined with other congenital malformations than is $\mathrm{CL}(\mathrm{P})$. In non-isolated clefts, congenital heart defects and neural tube defects are more frequently combined with oral clefts, in addition to other severe anomalies ${ }^{(15)}$.

The causes of oral clefts are largely unknown, but environmental factors such as maternal smoking, maternal use of drugs and maternal exposure to organic solvents are considered risk factors $^{(16)}$, and poor nutrition may also play a role ${ }^{(17)}$. Genetic

Abbreviations: CL(P), cleft lip with or without cleft palate; CPO, cleft palate only; MBRN, Medical Birth Registry of Norway; MoBa, Norwegian Mother and Child Cohort Study; RR, relative risk.

* Corresponding author: T. Gildestad, email trude.gildestad@uib.no 
factors and the interplay between genes and the environment are also important when exploring the causes of oral clefts ${ }^{(16)}$.

Norway introduced periconceptional folic acid recommendations to fertile women from 1998 onwards in an attempt to reduce the number of neural tube defects. There is no mandatory fortification of food supply with folic acid in Norway, unlike in many non-European countries. Since 1999, information on folic acid and multivitamin supplement use before and during pregnancy has been reported to the Medical Birth Registry of Norway (MBRN). In the present study, we investigated the association between women's use of folic acid and/or multivitamin supplements before pregnancy and the risk for oral cleft in the newborn, with and without accompanying birth defects, in all live births and stillbirths in Norway during 1999-2013.

\section{Methods}

\section{Data source}

Since 1967, live births and stillbirths from 16 weeks of gestation onwards have been notified to the MBRN, and, since 2002, notifications are required from 12 weeks of gestation ${ }^{(18,19)}$. The population-based registry comprises demographic data on the parents and extensive medical information on maternal health before and during pregnancy, the delivery and on the condition of the newborn, including birth defects and other neonatal diseases. Data are collected by a standardised notification form for each birth, which is completed by attending health personnel at the time of birth and during the stay at the delivery unit. From 1967 to December 1998, the notification form remained unchanged. A revised version was then introduced to include information on maternal vitamin supplement use, smoking before and during pregnancy and ultrasound dating. At the same time, a separate notification from neonatal intensive care units was introduced for all infants transferred to such units after birth. In 1999, a separate registry for pregnancy terminations after 12 gestational weeks was established within the MBRN. All terminations carried out because of congenital anomalies or diseases in the fetus have since been routinely added to the birth registry to increase the data quality on congenital anomalies.

\section{Vitamin supplementation}

Information on vitamin use includes questions on regular folic acid and multivitamin supplement use before and during pregnancy. Data were collected from 1999 on the revised version of the notification form through the following check boxes: 'Folic acid before pregnancy', 'Folic acid during pregnancy', 'Multivitamins before pregnancy' and 'Multivitamins during pregnancy'. Information on dose, frequency or exact duration of supplement use was not available. However, prenatal folic acid tablets used in Norway during the study period contained $0.4 \mathrm{mg}$, whereas most multivitamin supplements ranged from 0.0 to $0.2 \mathrm{mg}$ of folic acid $(20)$

We classified women as exposed before pregnancy (main exposure) if they used folic acid and/or multivitamins before pregnancy $(21.5 \%)$. The vast majority $(20.4 \%)$ of these women also used vitamins during pregnancy, whereas the minority used vitamins before pregnancy only (1.1\%) (Fig. 1). The exposure variable was included in the statistical regression models as categorical variables: no vitamin use; vitamin use before pregnancy $(21.5 \%)$; or vitamin use during pregnancy only. We also explored the use of folic acid alone (not concurrent with multivitamins) and the use of multivitamins alone (not concurrent with folic acid supplements). No use of vitamins (folic acid or multivitamin supplements) before or during pregnancy was used as the reference.

Unfortunately, data on terminated pregnancies do not include information on maternal folic acid or multivitamin supplement use. Consequently, our analyses focused on the relation between vitamin supplementation and oral clefts among live births and stillbirths from 1999 to 2013.

\section{Classification of birth defects}

Oral clefts were classified as follows: CPO (International Classification of Diseases (ICD)-10; Q 35), and CL(P) (ICD-10; Q 36-37). All oral clefts were also categorised as isolated or non-isolated. Isolated clefts were cleft cases with no major accompanying birth defects and less than three minor accompanying birth defects, defined according to the EUROCAT (European Surveillance of Congenital Anomalies) classification system ${ }^{(21,22)}$. Infants were classified as having registered major birth defects or not according to the same classification. Thus, infants classified with non-isolated oral clefts had at least one accompanying major birth defect or three or more minor accompanying birth defects. According to guidelines from EUROCAT, clefts with accompanying anencephaly or holoprosencephaly were not counted as clefts.

\section{Potential confounders}

Several known predictors of vitamin supplement use and predictors of oral clefts in the newborn were evaluated as potential confounders $^{(23)}$. These included parental age ( $<20$ (reference), 20-24, 25-29, 30-34, $\geq 35$ years), marital status (married/ co-habiting (reference), single, other), parity (0 (reference), $1, \geq 2$ previous births) and maternal smoking habits at the beginning of pregnancy (non-smoker (reference), occasional smoker, daily smoker, missing data). In addition, maternal epilepsy and pregestational diabetes (type 1, type 2 and unspecified diabetes before pregnancy) were included as potential confounding factors.

\begin{tabular}{|c|c|c|c|c|c|c|c|}
\hline Before & During & & $10 \%$ & $20 \%$ & $30 \%$ & $40 \%$ & $50 \%$ \\
\hline No & Yes & & & & & $35.3 \%$ & \\
\hline Yes & Yes & & & $20.4 \%$ & & & \\
\hline Yes & No & $1.1 \%$ & & & & & \\
\hline No & No & & & & & & $43.2 \%$ \\
\hline
\end{tabular}

Fig. 1. Reported vitamin use, folic acid and/or multivitamins before and/or during pregnancy, to the Medical Birth Registry of Norway, 1999-2013. 'No' represents no vitamin supplement use; 'yes' represents use of vitamin supplements before and/or during pregnancy. 


\section{Statistical analyses}

Log-binomial regression was applied to investigate associations between maternal use of vitamins before pregnancy and the risk for oral clefts in infants, using Stata version 12.1 (Stata Corp.). Relative risks (RR) with 95\% confidence intervals were reported with and without adjustment for the abovementioned potential confounders. Fig. 1 and 2 were made in $\mathrm{R}$ version $3.1 .1^{(24)}$.

\section{Ethical approval}

This study was approved by the Regional Medical Ethics Committee of Western Norway.

\section{Results}

\section{Study population}

In the study period (1999-2013), a total of 528220 women had 880568 pregnancies resulting in 896674 live births and stillbirths ( $\geq 22$ weeks of gestation or birth weight $\geq 500 \mathrm{~g}$ ), and 3378 pregnancy terminations ( $\geq 12$ weeks). The total number of oral clefts was 1714; among them 1623 (94.7\%) were in live births or stillbirths, and ninety-one (5.3\%) were in terminated pregnancies. The birth prevalence of oral clefts was $1 \cdot 81 / 1000$ live births and stillbirths. The distributions of clefts among live births, stillbirths, neonatal deaths (during the first $28 \mathrm{~d}$ of life) and postneonatal deaths (from 28 to $364 \mathrm{~d}$ ) as well as in terminated pregnancies are shown in Table 1 . Among all clefts, the reported frequency of non-isolated clefts was $23.3 \%$ ( $n$ 400), whereas $76.7 \%$ were reported as isolated clefts ( $n$ 1314). Among infants with CPO, $30.0 \%$ were classified as non-isolated clefts ( $n$ 183), whereas $19.7 \%$ of those with CL(P) were non-isolated ( $n$ 217).
Parental characteristics are shown in Table 2. Folic acid and/or multivitamin use before and during pregnancy was reported by $20.4 \%$ of the women, whereas $1.1 \%$ of the women used vitamin supplements before pregnancy only; thus, $21.5 \%$ of women were identified as having been exposed before pregnancy. Use of vitamin supplements during pregnancy only was reported by $35.3 \%$. In subgroups of women exposed to vitamins before pregnancy, we identified users of folic acid alone (not concurrent with multivitamins) in $8.1 \%$ of the women and multivitamins alone (not concurrent with folic acid) in $2.1 \%$. Among women exposed before pregnancy, more women ( $55.6 \%$ ) combined the use of folic acid with the use of multivitamins, whereas $38.3 \%$ of multivitamin users also took folic acid.

The overall proportion of women reporting no vitamin use before or during pregnancy was $43.2 \%$ (Fig. 1).

\section{Folic acid and multivitamin supplement use}

Table 3 shows the association between maternal folic acid and/ or multivitamins and infant oral clefts. For women exposed to vitamins before pregnancy, the adjusted RR was 0.90 (95\% CI $0.79,1.04)$ for clefts overall, and 0.84 (95\% CI $0.66,1.06)$ and 0.94 (95\% CI $0.79,1.13)$ for CPO and CL(P), respectively.

Fig. 2 shows the adjusted RR for oral clefts in the newborn to women exposed to vitamins before pregnancy in relation to non-users. Results are shown for clefts overall, CPO and CL(P), as well as for the subgroups non-isolated and isolated clefts. Among non-isolated clefts, vitamin use was significantly associated with a lower risk for total clefts with the adjusted RR being 0.63 (95\% CI $0.45,0.88$ ). To explore this finding we performed sub-analyses after excluding infants with oral clefts and accompanying chromosomal abnormalities ( $n$ 52) and genetic syndromes ( $n$ 21): in total seventy-one infants.

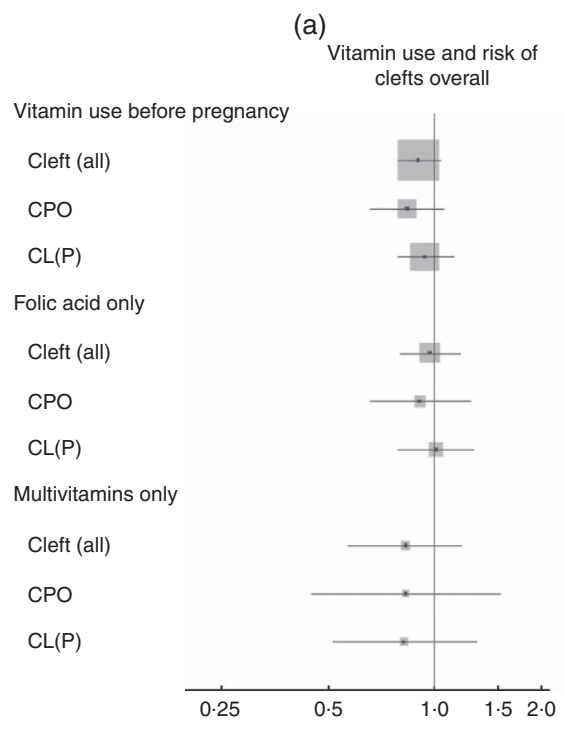

(b)

Vitamin use and risk of non-isolated clefts

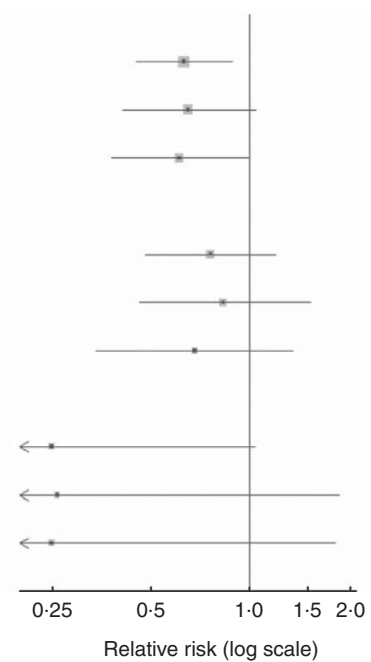

(c) Vitamin use and risk of isolated clefts

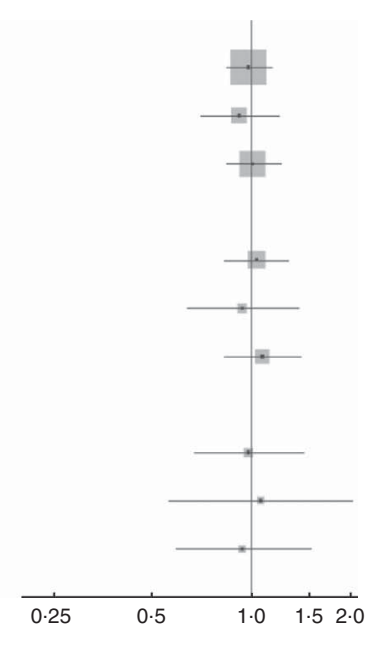

Fig. 2. Adjusted ${ }^{\star}$ relative risks ( $95 \%$ confidence intervals) for oral clefts overall and in subgroups of non-isolated or isolated oral clefts associated with folic acid and/or multivitamin supplements †, Norway 1999-2013. Area of squares is proportional to the number of cases in each group. * Adjusted for year of childbirth, maternal and paternal age, marital status, parity, maternal smoking, maternal epilepsy and pregestational diabetes. † Reported use of folic acid and/or multivitamin supplements, including $20.4 \%$ who reported use both before and during pregnancy and $1.1 \%$ of women who reported use of supplements before pregnancy only. CPO, cleft palate only; CL(P), cleft lip with or without cleft palate. 
Table 1. Oral clefts in live births, stillbirths, neonatal deaths, postneonatal deaths and pregnancy terminations among 900052 births and terminations, Norway, 1999-2013

(Numbers and percentages)

\begin{tabular}{|c|c|c|c|c|c|c|c|c|c|c|c|}
\hline \multirow[b]{2}{*}{ Diagnosis (ICD-10) } & \multicolumn{2}{|c|}{ Live births* } & \multicolumn{2}{|c|}{ Stillbirths } & \multicolumn{2}{|c|}{ Neonatal deaths $†$} & \multicolumn{2}{|c|}{ Postneonatal deaths $\ddagger$} & \multicolumn{2}{|c|}{ Terminated pregnancies } & \multirow[b]{2}{*}{ Total } \\
\hline & $n$ & $\%$ & $n$ & $\%$ & $n$ & $\%$ & $n$ & $\%$ & $n$ & $\%$ & \\
\hline All clefts & 1539 & $89 \cdot 8$ & 29 & 1.7 & 34 & $2 \cdot 0$ & 21 & $1 \cdot 2$ & 91 & $5 \cdot 3$ & 1714 \\
\hline CPO (Q 35) & 558 & 91.5 & 11 & $1 \cdot 8$ & 11 & 1.8 & 6 & 1.0 & 24 & 3.9 & 610 \\
\hline $\mathrm{CL}(\mathrm{P})(\mathrm{Q} 36-37)$ & 981 & 88.9 & 18 & 1.6 & 23 & $2 \cdot 1$ & 15 & 1.4 & 67 & $6 \cdot 0$ & 1104 \\
\hline Isolated clefts§ & 1299 & $98 \cdot 9$ & 9 & 0.7 & 1 & 0.1 & 2 & 0.1 & 3 & 0.2 & 1314 \\
\hline $\mathrm{CPO}$ & 423 & $99 \cdot 1$ & 3 & 0.7 & 0 & 0.0 & 0 & 0.0 & 1 & 0.2 & 427 \\
\hline$C L(P)$ & 876 & $98 \cdot 8$ & 6 & 0.7 & 1 & 0.1 & 2 & 0.2 & 2 & 0.2 & 887 \\
\hline Non-isolated clefts\|l & 240 & $60 \cdot 0$ & 20 & 5.0 & 33 & $8 \cdot 3$ & 19 & 4.7 & 88 & $22 \cdot 0$ & 400 \\
\hline $\mathrm{CPO}$ & 135 & 73.8 & 8 & $4 \cdot 3$ & 11 & 6.0 & 6 & $3 \cdot 3$ & 23 & $12 \cdot 6$ & 183 \\
\hline $\mathrm{CL}(\mathrm{P})$ & 105 & $48 \cdot 4$ & 12 & 5.5 & 22 & 10.1 & 13 & 6.0 & 65 & $30 \cdot 0$ & 217 \\
\hline
\end{tabular}

$\mathrm{CPO}$, cleft palate only; $\mathrm{CL}(\mathrm{P})$, cleft lip with or without cleft palate.

* Live births excluding neonatal and postneonatal deaths.

$\dagger$ Neonatal deaths were deaths occurring during the first $28 \mathrm{~d}$ postpartum in live born infants.

$\ddagger$ Postneonatal deaths occurred from $28 \mathrm{~d}$ postpartum to 1 year of age.

$\S$ Isolated clefts were classified as cleft cases with no major accompanying birth defects and less than three minor accompanying birth defects defined according to a EUROCAT ${ }^{(2)}$ classification system.

\| Non-isolated clefts were classified as cleft cases with major accompanying birth defects and/or three or more minor accompanying birth defects. Clefts with accompanying anencephalies or holoprosencephalies on were not counted as oral clefts according to EUROCAT guidelines.

Table 2. Parental characteristics by maternal use of folic acid and multivitamin supplement before and/or during pregnancy among live births and stillbirths in Norway, 1999-2013

(Numbers and percentages)

\begin{tabular}{|c|c|c|c|c|c|c|c|}
\hline \multirow[b]{3}{*}{ Parental characteristics } & \multirow[b]{3}{*}{ Total ( $n 880568)(100 \%)$} & \multicolumn{6}{|c|}{ Vitamin supplement use } \\
\hline & & \multicolumn{2}{|c|}{$\begin{array}{l}\text { No use of vitamins } \\
(n 380273)(43 \cdot 2 \%)\end{array}$} & \multicolumn{2}{|c|}{$\begin{array}{l}\text { Use of vitamins before pregnancy } \\
\qquad(n 189217)(21.5 \%)^{\star}\end{array}$} & \multicolumn{2}{|c|}{$\begin{array}{l}\text { Use of vitamins during pregnancy } \\
\text { only }(n 311078)(35.3 \%)\end{array}$} \\
\hline & & $n$ & $\%$ & $n$ & $\%$ & $n$ & $\%$ \\
\hline \multicolumn{8}{|l|}{ Maternal age (years) } \\
\hline$<20$ & 19701 & 11376 & $57 \cdot 7$ & 1503 & $7 \cdot 6$ & 6822 & 34.6 \\
\hline $20-24$ & 129518 & 62245 & $48 \cdot 1$ & 17620 & $13 \cdot 6$ & 49653 & $38 \cdot 3$ \\
\hline $25-29$ & 284902 & 121286 & $42 \cdot 6$ & 58805 & $20 \cdot 6$ & 104811 & $36 \cdot 8$ \\
\hline $30-34$ & 291329 & 120672 & 41.4 & 71112 & 24.4 & 99545 & 34.2 \\
\hline$>34$ & 155038 & 64640 & 41.7 & 40167 & $25 \cdot 9$ & 50231 & $32 \cdot 4$ \\
\hline Missing data & 80 & 54 & 67.5 & 10 & $12 \cdot 5$ & 16 & $20 \cdot 0$ \\
\hline \multicolumn{8}{|l|}{ Paternal age (years) } \\
\hline$<20$ & 5403 & 3093 & $57 \cdot 3$ & 398 & 7.4 & 1912 & 35.4 \\
\hline $20-24$ & 61873 & 29572 & $47 \cdot 8$ & 7997 & $12 \cdot 9$ & 24304 & $39 \cdot 3$ \\
\hline $25-29$ & 205013 & 88196 & 43.0 & 39425 & $19 \cdot 2$ & 77392 & 37.8 \\
\hline $30-34$ & 295155 & 122914 & 41.6 & 68505 & $23 \cdot 2$ & 103736 & $35 \cdot 1$ \\
\hline$>34$ & 301515 & 130198 & 43.2 & 71135 & 23.6 & 100182 & 33.2 \\
\hline Missing data & 11609 & 6300 & 54.3 & 1757 & $15 \cdot 1$ & 3552 & 30.6 \\
\hline \multicolumn{8}{|l|}{ Maternal smoking } \\
\hline Non-smokers & 616276 & 225476 & $36 \cdot 6$ & 152948 & $24 \cdot 8$ & 237852 & 38.6 \\
\hline Occasional smokers & 14399 & 6240 & 43.3 & 2555 & $17 \cdot 7$ & 5604 & 38.9 \\
\hline Daily smokers & 105997 & 54763 & 51.6 & 13764 & 13.0 & 37470 & 35.4 \\
\hline Missing data & 143896 & 93794 & $65 \cdot 2$ & 19950 & 13.9 & 30152 & $20 \cdot 9$ \\
\hline \multicolumn{8}{|l|}{ Parity } \\
\hline 0 & 365240 & 144018 & $39 \cdot 4$ & 78846 & $21 \cdot 6$ & 142376 & 39.0 \\
\hline 1 & 314440 & 133828 & 42.6 & 72988 & 23.2 & 107624 & 34.2 \\
\hline$\geq 2$ & 200888 & 102427 & 51.0 & 37383 & 18.6 & 61078 & $30 \cdot 4$ \\
\hline \multicolumn{8}{|l|}{ Marital status } \\
\hline Married & 419591 & 184842 & $44 \cdot 0$ & 96188 & $22 \cdot 9$ & 138561 & 33.0 \\
\hline Co-habitant & 391260 & 157721 & 40.3 & 84168 & 21.5 & 149371 & 38.2 \\
\hline Single & 58995 & 30670 & 52.0 & 7678 & 13.0 & 20647 & 35.0 \\
\hline Other & 10722 & 7040 & 65.6 & 1183 & 11.0 & 2499 & 23.3 \\
\hline \multicolumn{8}{|l|}{ Pregestational diabetes } \\
\hline No & 874461 & 377461 & 43.2 & 187871 & 21.5 & 309129 & $35 \cdot 3$ \\
\hline Yes & 6107 & 2812 & $46 \cdot 1$ & 1346 & $22 \cdot 0$ & 1949 & 31.9 \\
\hline \multicolumn{8}{|l|}{ Epilepsy } \\
\hline No & 874135 & 378099 & 43.2 & 187398 & 21.4 & 308638 & $35 \cdot 3$ \\
\hline Yes & 6433 & 2174 & 33.8 & 1819 & $28 \cdot 3$ & 2440 & 37.9 \\
\hline
\end{tabular}

${ }^{*}$ Reported use of folic acid and/or multivitamin supplements, including $20.4 \%$ who reported use both before and during pregnancy and $1.1 \%$ of women who reported use of supplements before pregnancy only. 
Table 3. Crude and adjusted relative risks (RR) for oral clefts by folic acid and/or multivitamin supplement use, Norway 1999-2013 (Relative risks and $95 \%$ confidence intervals)

\begin{tabular}{|c|c|c|c|c|c|c|}
\hline \multirow[b]{2}{*}{ Vitamin supplement use $(n(\%))$} & \multirow[b]{2}{*}{ Diagnosis } & \multirow[b]{2}{*}{ Number of clefts } & \multicolumn{2}{|c|}{ Crude } & \multicolumn{2}{|c|}{ Adjusted ${ }^{*}$} \\
\hline & & & RR & $95 \% \mathrm{Cl}$ & $\mathrm{RR}$ & $95 \% \mathrm{Cl}$ \\
\hline \multirow[t]{4}{*}{ No use of vitamins ( $n 380273$ (43.2)) } & & & \multicolumn{2}{|c|}{ Ref. } & \multicolumn{2}{|r|}{ Ref. } \\
\hline & Cleft (all) & 742 & \multicolumn{2}{|c|}{-} & \multirow{2}{*}{\multicolumn{2}{|c|}{-}} \\
\hline & $\mathrm{CPO}$ & 276 & \multicolumn{2}{|c|}{-} & & \\
\hline & $C L(P)$ & 466 & & - & & - \\
\hline \multicolumn{7}{|l|}{ Use of vitamins before pregnancy† } \\
\hline \multicolumn{7}{|c|}{ Folic acid and/or multivitamins ( $n 189217$ (21.5)) } \\
\hline & Cleft (all) & 328 & 0.88 & $0.77,1.00$ & 0.90 & $0.79,1.04$ \\
\hline & $\mathrm{CPO}$ & 116 & 0.84 & $0.67,1.04$ & 0.84 & $0.66,1.06$ \\
\hline & $\mathrm{CL}(\mathrm{P})$ & 212 & 0.91 & $0.77,1.07$ & 0.94 & $0.79,1.13$ \\
\hline \multicolumn{7}{|c|}{ Use of vitamins during pregnancy only $\ddagger$} \\
\hline \multicolumn{7}{|c|}{ Folic acid and/or multivitamins ( $n 311078$ (35.3)) } \\
\hline & Cleft (all) & 558 & 0.95 & $0.74,0.99$ & 0.93 & $0.83,1.05$ \\
\hline & $\mathrm{CPO}$ & 197 & 0.87 & $0.72,1.04$ & 0.87 & $0.71,1.06$ \\
\hline & $\mathrm{CL}(\mathrm{P})$ & 361 & 0.94 & $0.82,1.08$ & 0.97 & $0.84,1 \cdot 13$ \\
\hline \multicolumn{7}{|c|}{ Subgroups of vitamin use before pregnancy } \\
\hline \multicolumn{7}{|l|}{ Folic acid only $(n 71615(8.1)) \S$} \\
\hline & CPO & 48 & 0.91 & $0.67,1.24$ & 0.91 & $0.66,1.26$ \\
\hline & $\mathrm{CL}(\mathrm{P})$ & 84 & 0.95 & $0.75,1.20$ & 1.01 & $0.79,1.29$ \\
\hline \multicolumn{7}{|l|}{ Multivitamins only $(n 18799(2 \cdot 1)) \|$} \\
\hline & Cleft (all) & 32 & 0.87 & $0.61,1.24$ & 0.83 & $0.57,1.19$ \\
\hline & $\mathrm{CPO}$ & 11 & 0.80 & $0.44,1.47$ & 0.83 & $0.45,1.53$ \\
\hline & $C L(P)$ & 21 & 0.91 & $0.59,1.41$ & 0.82 & $0.52,1.31$ \\
\hline
\end{tabular}

Ref., referent values; CPO, cleft palate only; $C L(P)$, cleft lip with or without cleft palate.

* Adjusted for year of childbirth, maternal and paternal age, marital status, parity, maternal smoking, maternal epilepsy and pregestational diabetes.

† Reported use of folic acid and/or multivitamin supplements, including $20.4 \%$ who reported use both before and during pregnancy and $1.1 \%$ of women who reported use of supplements before pregnancy only.

$\ddagger$ No use of vitamin supplements before pregnancy.

$\S$ Reported use of folic acid supplements (not concurrent with multivitamins).

॥ Reported use of multivitamin supplements (not concurrent with folic acid supplements, but most multivitamins contain $0.0-0.2 \mathrm{mg}$ of folic acid).

The adjusted RR of overall clefts remained nearly unchanged (adjusted RR 0.94; $95 \%$ CI 0.81, 1.08), but changed slightly for vitamin use and non-isolated clefts (adjusted RR 0.54; $95 \% \mathrm{CI}$ 0.34, 0.85). After excluding chromosomal abnormalities and genetic syndromes, the associated anomalies found in combination with oral clefts were mainly heart defects ( $n$ 69), limb defects (not including hip dysplasia/dislocation) ( $n$ 50), urinary tract defects ( $n$ 33), nervous system defects ( $n$ 29, of which six were neural tube defects), digestive defects ( $n$ 27), ear, nose and throat defects ( $n$ 25) and genital defects ( $n$ 20). When we excluded cleft cases with heart defects ( $n$ 69), the relations remained nearly unchanged for both clefts overall and nonisolated oral clefts. The same was true when excluding cleft cases with accompanying nervous system defects ( $n$ 29). When excluding limb defects ( $n$ 50), the association was almost unchanged for clefts overall, but slightly weaker for nonisolated clefts (RR 0.67; $95 \%$ CI 0.40, 1.11), and was no longer statistically significant.

We found no significant association between women exposed to vitamins and isolated oral clefts. The adjusted RR for all isolated clefts was 0.98 (95\% CI 0.84, 1.15); for CPO the adjusted RR was $0.92(95 \%$ CI $0.70,1.21)$ and for CL(P) the RR was $1.01(0.84,1.23)$. We also divided our study period into two different time intervals (1999-2005 and 2006-2013). We did find a significantly reduced risk for oral clefts overall by vitamin use in the first period (the adjusted RR $0.76 ; 95 \%$ CI $0.59,0.97$ ), but not in the second (the adjusted RR 1.07; $95 \%$ CI 0.88, 1.29).
Adjustment for potential confounding factors did not change the estimates substantially (Table 3). Maternal smoking was strongly associated with both vitamin use and oral clefts. Occasional smokers and daily smokers were less likely to use vitamin supplements than were non-smokers, and daily smoking during pregnancy was associated with increased infant risk for oral cleft (RR 1.36; $95 \%$ CI $1 \cdot 19,1 \cdot 56$ ). Information on smoking habits was missing for nearly $17 \%$ of the women. The final model was analysed with and without missing data on smoking habits. In analyses restricted to women with complete smoking information, no major changes in the risk estimates were seen; the adjusted RR for oral clefts overall was $0.93(95 \%$ CI $0.79,1.08)$ and that for non-isolated oral clefts was 0.53 (95\% CI 0.32, 0.87). All analyses have been performed for various combinations of folic acid and/or multivitamin supplement use before and/or during pregnancy and risk for oral clefts in the newborn, with essentially similar results (data not shown).

\section{Discussion}

In this large population-based study of 528220 women and 880568 pregnancies, 1623 newborns or stillborns were affected by oral clefts in Norway in the time period 1999-2013. Use of folic acid and/or multivitamins before pregnancy was reported by $21.5 \%$ of the women. We found no association between maternal supplement use and risk for oral clefts in the newborn overall. Women who used vitamin supplements did, however, have a significantly lower risk for non-isolated oral clefts in the newborn. 


\section{Comparisons with previous studies}

Our study showed no risk reduction for oral clefts overall among live born or stillborn infants to women using vitamins before pregnancy, a finding supported by other observational studies $^{(25,26)}$. However, yet other studies have shown associations between vitamin use and oral clefts ${ }^{(27,28)}$. Consequently, the evidence is mixed and is likely caused by differences in design, sample selection and study size, different measures of vitamins and classifications of oral clefts. It may also be that the underlying nutritional status of the general population of the place where the study is conducted is of importance.

A population-based case-control study from 2007 by Wilcox et al. explored the role of folate in the prevention of oral clefts in the time period 1996-2001 in Norway. They found a 39\% decrease in $\mathrm{CL}(\mathrm{P})$ risk associated with using folic acid supplements and a $64 \%$ decrease when women used folic acid supplements in addition to a folate-rich diet ${ }^{(8)}$. This study partly overlapped with our study population, outcome data and time period (3-year overlap), but differed in terms of collection of exposure information. Our study was registry based, where information about maternal vitamin use was reported to the population-based MBRN for all live births and stillbirths during 1999-2013, whereas Wilcox's study was a case-control study in which information on vitamin use was collected months after delivery. There were contradictory findings for the subtypes of oral clefts in the two studies. Differences in the study design, time periods, cleft populations, sample size and exposure information may have played a role. When we divided our study period into two (1999-2005 and 2006-2013), we found a significantly reduced risk for oral clefts overall by vitamin use in the first time period, closer in time to Wilcox's study, but not in the second.

A Hungarian study reported $20-30 \%$ risk reduction for oral clefts associated with the use of high-dose folic acid $(3-6 \mathrm{mg} / \mathrm{d})^{(29)}$. Other studies have also shown a dose-dependent effect of vitamins on oral clefts ${ }^{(30,31)}$. Some studies have shown a risk reduction for $\mathrm{CL}(\mathrm{P})$, but not for $\mathrm{CPO}^{(8,28)}$. In a meta-analysis by Johnson \& Little $^{(32)}$, use of multivitamin supplements was inversely associated with CL(P), but to a lesser extent with CPO. There was not enough evidence to prove an association between folate or folic acid and oral clefts, but there was substantial heterogeneity between studies $^{(32)}$. In a meta-analysis by Badovinac et al. ${ }^{(7)}$, estimates from case-control studies showed that use of folic acid-containing supplements during pregnancy decreased the risk for any oral cleft by $33 \%$, that for cleft lip and palate by $29 \%$ and that for CPO by $20 \%$. Estimates among prospective studies were in the same protective direction for any oral cleft (45\%) and for cleft lip and palate (49\%). However, the prospective studies indicated that supplement use increased the risk for CPO by $19 \%{ }^{(7)}$.

\section{Strengths and limitations}

The strength of our study includes a large study population with information on maternal vitamin use for all live births and stillbirths in Norway during 1999-2013. Together with comprehensive information on maternal determinants of health, this gave us the opportunity to study women's use of folic acid and multivitamins and its association with oral clefts in the newborn. However, our study had some limitations. Misclassification of exposure may have biased the association measures due to possible incorrect reporting of vitamin supplement use by the hospitals. This could include misclassification regarding time and type of vitamin use, and also missing data on vitamin use. We were not able to identify missing data on vitamin use in this study. Therefore, some women may have been misclassified as non-users although being vitamin users.

The prevalence of folic acid and/or multivitamin supplement use is somewhat lower in the MBRN compared with what has been found in two Norwegian studies based on the Norwegian Mother and Child Cohort Study $(\mathrm{MoBa})^{(23,33)}$. In the MoBa population (giving birth 1999-2009), use of folic acid in the period 1-4 weeks before the start of pregnancy was reported by $33 \%$ of participating women, whereas $50 \%$ reported use of folic acid during the early weeks of pregnancy. However, the MoBa study, although nationwide, consists of a quite selected population, with strong under-representation of younger women $(<25$ years), single mothers, multiparous mothers, smokers and mothers with low education $^{(34)}$. All these factors may be associated with maternal periconceptional use of folic acid. The MBRN, on the other hand, includes all women giving birth in Norway and thus a nonselected population, and this may partly explain the difference in the registered use of folic acid between the two populations.

Regarding unplanned pregnancies, we only know one study in Norway addressing this issue. In one of the mentioned studies based on the MoBa population ${ }^{(33)}$, about $20 \%$ of the women did not plan their pregnancy. As the MoBa population is a selected population, the actual numbers of unplanned pregnancies among Norwegian women are most likely higher, but this is not known. However, the lower prevalence of vitamin supplement use before conception in the whole population of Norwegian women most likely reflects a higher rate of unplanned pregnancies.

We expected a lower ascertainment for $\mathrm{CPO}$ than for $\mathrm{CL}(\mathrm{P})$, as a previous study showed that reporting of oral clefts to the MBRN, 1967-1998, was dependent on the severity of the cleft. Of all cleft cases recorded in the MBRN, $57 \%$ of $\mathrm{CPO}$ and $94 \%$ of CL(P) live birth cases had been recorded ${ }^{(35)}$. CPO is more frequently associated with other birth defects, which likely increases the ascertainment of non-isolated CPO. We found the prevalence of oral clefts overall to be $1 \cdot 81 / 1000$ live and stillbirths in our study (0.65/ 1000 for $\mathrm{CPO}$ and $1 \cdot 16 / 1000$ for $\mathrm{CL}(\mathrm{P}))$. This is a lower prevalence compared with the findings of another Norwegian study from the period 1967 to $1998^{(14)}$ and indicates that a few oral clefts may have been under-reported after 1998, or that termination of pregnancy for oral clefts has been increasing since 1998. However, the percentage of terminated pregnancies with cases of oral clefts among the total number of oral clefts only increased from $1.4 \%$ in 1999 to $4.0 \%$ in 2013 (http://mfr-nesstar.uib.no/ $\mathrm{mfr} /$ ) and should not have affected the association of vitamin use with non-isolated clefts. Further, it seems that heart defects and neural tube defects cannot explain the strong association of vitamin use with non-isolated oral clefts.

Associations in observational studies may be subject to unknown or residual confounding ${ }^{(36)}$. Several factors were not available in our study, like information on maternal dietary intake, alcohol consumption and maternal BMI. It is possible that other healthy behaviours - for instance, healthy diets - are 
also more common in vitamin supplement users. However, we did adjust for maternal age, smoking and marital status, which could partly explain the patterns in use of folic acid and multivitamins and could also affect the prevalence of oral clefts.

We found a stronger effect on oral clefts with multivitamins than with folic acid. However, because most multivitamin supplements in Norway contain some folic acid, ranging from 0.0 to $0.2 \mathrm{mg}$, it is not possible to create a multivitamin group without folic acid within our data. As the association is somewhat stronger for this group than for the folic acid-only group, it seems that other micronutrients than folic acid may also play a role, or that the association is confounded by lifestyle factors associated with the use of multivitamins only.

Maternal smoking has been associated with increased risk for oral clefts ${ }^{(37,38)}$, also present in our study. However, adjusting for smoking only slightly attenuated the associations between vitamin use and oral clefts. We also restricted analyses to women with complete smoking information. As this did not affect the association of vitamin use with risk for oral cleft, it is not likely that results would be different among women with missing smoking information.

\section{Conclusion}

We found no statistically significant association between use of vitamins before pregnancy and isolated oral clefts in the newborn. We did, however, find lower risk for oral clefts that occurred in combination with other malformations.

\section{Acknowledgements}

This study was funded by The Western Norway Regional Health Authority, project numbers 911647 and 911629 (N. Ø.).

T. G., T. B., K. K., S. E. V., R. M. N., Ø. A. H. and N. Ø. all substantially contributed to conception, design and interpretation of data. T. G. drafted the article and analysed the data. All the authors revised it critically for important intellectual content and gave their approval of the final version.

There are no conflicts of interest to declare.

\section{References}

1. Smithells RW, Sheppard S, Schorah CJ, et al. (1980) Possible prevention of neural-tube defects by periconceptional vitamin supplementation. Lancet 1, 339-340.

2. Milunsky A, Jick H, Jick SS, et al. (1989) Multivitamin/folic acid supplementation in early pregnancy reduces the prevalence of neural tube defects. JAMA 262, 2847-2852.

3. MRC Vitamin Study Research Group (1991) Prevention of neural tube defects: results of the Medical Research Council Vitamin Study. Lancet 338, 131-137.

4. Czeizel AE \& Dudas I (1992) Prevention of the first occurrence of neural-tube defects by periconceptional vitamin supplementation. $N$ Engl J Med 327, 1832-1835.

5. Berry RJ, Li Z, Erickson JD, et al. (1999) Prevention of neuraltube defects with folic acid in China. China-U.S. Collaborative Project for Neural Tube Defect Prevention. N Engl J Med 341, 1485-1490.

6. Botto LD, Moore CA, Khoury MJ, et al. (1999) Neural-tube defects. $N$ Engl J Med 341, 1509-1519.
7. Badovinac RL, Werler MM, Williams PL, et al. (2007) Folic acid-containing supplement consumption during pregnancy and risk for oral clefts: a meta-analysis. Birth Defects Res $A$ Clin Mol Teratol 79, 8-15.

8. Wilcox AJ, Lie RT, Solvoll K, et al. (2007) Folic acid supplements and risk of facial clefts: national population based casecontrol study. BMJ 334, 464.

9. Kelly D, O'Dowd T \& Reulbach U (2012) Use of folic acid supplements and risk of cleft lip and palate in infants: a population-based cohort study. BrJ Gen Pract 62, e466-e472.

10. Rozendaal AM, van Essen AJ, te Meerman GJ, et al. (2013) Periconceptional folic acid associated with an increased risk of oral clefts relative to non-folate related malformations in the Northern Netherlands: a population based case-control study. Eur J Epidemiol 28, 875-887.

11. Shaw GM, Lammer EJ, Wasserman CR, et al. (1995) Risks of orofacial clefts in children born to women using multivitamins containing folic acid periconceptionally. Lancet 346, 393-396.

12. Mossey PA, Little J, Munger RG, et al. (2009) Cleft lip and palate. Lancet 374, 1773-1785.

13. Mossey PA \& Modell B (2012) Epidemiology of oral clefts 2012: an international perspective. Front Oral Biol 16, 1-18.

14. Sivertsen A, Wilcox A, Johnson GE, et al. (2008) Prevalence of major anatomic variations in oral clefts. Plast Reconstr Surg 121, 587-595.

15. Wyszynski DF (2002) Cleft Lip and Palate: From Origin to Treatment. Oxford: Oxford University Press.

16. Watkins SE, Meyer RE, Strauss RP, et al. (2014) Classification, epidemiology, and genetics of orofacial clefts. Clin Plast Surg 41, 149-163.

17. Wyszynski DF (2002) Maternal nutrition and oral clefts. In Cleft Lip and Palate: From Origin to Treatment, pp. 170-192 [RG Munger, editor]. Oxford: Oxford University Press.

18. Irgens LM (2000) The Medical Birth Registry of Norway. Epidemiological research and surveillance throughout 30 years. Acta Obstet Gynecol Scand 79, 435-439.

19. Irgens LM (2008) Medisinske Registre. Oslo: Gyldendal akademisk.

20. VKM (2015) Risk assessment of folic acid in food supplements. Scientific opinion of the Panel on Nutrition, Dietetic Products, Novel Food and Allergy, VKM Report 2015:05. Oslo, Norway. www.vkm.no (accessed April 2015).

21. European Surveillance of Congenital Anomalies (2005/2011) Instructions for the registration and surveillance of congenital anomalies. EUROCAT Guide 13. http://www.eurocat-network. $\mathrm{eu} /$ default.aspx?tree = aboutus $\% 2 \mathrm{fwh}$ atiseurocat $\% 2 \mathrm{fw}$ whatiseurocat (accessed 10 September 2013).

22. EUROCAT (2014) Malformation coding guides; minor anomalies for exclusion. http://www.eurocat-network.eu/content/EUROCAT-Guide-1.4-Section-3.2.pdf (accessed April 2014).

23. Nilsen RM, Vollset SE, Gjessing HK, et al. (2006) Patterns and predictors of folic acid supplement use among pregnant women: the Norwegian Mother and Child Cohort Study. Am J Clin Nutr 84, 1134-1141.

24. R Core Team (2014) $R$ : A Language and Environment for Statistical Computing, vol $R v$. 3.1.1. Vienna: R Foundation for Statistical Computing.

25. Little J, Gilmour M, Mossey PA, et al. (2008) Folate and clefts of the lip and palate - a U.K.-based case-control study: Part I: dietary and supplemental folate. Cleft Palate Craniofac J 45, 420-427.

26. Shaw GM, Carmichael SL, Laurent C, et al. (2006) Maternal nutrient intakes and risk of orofacial clefts. Epidemiology 17, 285-291.

27. Botto LD, Olney RS \& Erickson JD (2004) Vitamin supplements and the risk for congenital anomalies other than neural tube defects. Am J Med Genet C Semin Med Genet 125C, 12-21. 
28. van Rooij IA, Ocke MC, Straatman H, et al. (2004) Periconceptional folate intake by supplement and food reduces the risk of nonsyndromic cleft lip with or without cleft palate. Prev Med 39, 689-694.

29. Czeizel AE, Toth M \& Rockenbauer M (1996) Populationbased case control study of folic acid supplementation during pregnancy. Teratology 53, 345-351.

30. Czeizel AE, Timar L \& Sarkozi A (1999) Dose-dependent effect of folic acid on the prevention of orofacial clefts. Pediatrics 104, e66.

31. Czeizel AE (2004) The primary prevention of birth defects: multivitamins or folic acid? Int J Med Sci 1, 50-61.

32. Johnson CY \& Little J (2008) Folate intake, markers of folate status and oral clefts: is the evidence converging? Int $\mathrm{J}$ Epidemiol 37, 1041-1058.

33. Suren P, Roth C, Bresnahan M, et al. (2013) Association between maternal use of folic acid supplements and risk of autism spectrum disorders in children. IAMA 309 , $570-577$.

34. Nilsen RM, Vollset SE, Gjessing HK, et al. (2009) Self-selection and bias in a large prospective pregnancy cohort in Norway. Paediatr Perinat Epidemiol 23, 597-608.

35. Kubon C, Sivertsen A, Vindenes HA, et al. (2007) Completeness of registration of oral clefts in a medical birth registry: a populationbased study. Acta Obstet Gynecol Scand 86, 1453-1457.

36. Lawlor DA, Davey Smith G, Kundu D, et al. (2004) Those confounded vitamins: what can we learn from the differences between observational versus randomised trial evidence? Lancet 363, 1724-1727.

37. Honein MA, Rasmussen SA, Reefhuis J, et al. (2007) Maternal smoking and environmental tobacco smoke exposure and the risk of orofacial clefts. Epidemiology 18, 226-233.

38. Little J, Cardy A \& Munger RG (2004) Tobacco smoking and oral clefts: a meta-analysis. Bull World Health Organ 82, 213-218. 